\title{
A Economia Solidária no Brasil e o desuso do mecanismo frente à outras políticas públicas: Um estudo de evidências por meio da literatura especializada
}

\author{
The Solidarity Economy in Brazil and the disuse of the mechanism in relation to other public
}

policies: A study of evidence through specialized literature

La Economía Solidaria en Brasil y el desuso del mecanismo en relación con otras políticas públicas: un estudio de la evidencia a través de la literatura especializada

\begin{abstract}
Resumo
Apesar da dificuldade de conceituar a Economia Solidária (ES) devido a temas interconectados e utilizados como sinônimos, é equívoca seu isoladamente do contexto de desenvolvimento econômico como uma alternativa de geração de renda familiar. Com a realidade social e econômica das regiões do extenso território brasileiro, percebe-se um ofuscamento da função social que a ES exerce no campo das Políticas Públicas que compõem a agricultura familiar que entre outros desdobramentos em termos de políticas governamentais, está prevista como uma das metas dos 17 Objetivos do Desenvolvimento Sustentável para 2030, da Organização das Nações Unidas, caracterizando-se como instrumento nacional e internacional de fomento. O método se consiste em análise descritiva e documental, utilizando abordagem quantitativa e bibliográfica quanto à representação dos dados. Foi constatado um desalinhamento dos eixos que fomentam as políticas públicas com o desenvolvimento sustentável, e a ES foi esquecida e em certa medida sufocada pelo sistema capitalista nas quais políticas públicas inclusivas não conseguem absorver esse fenômeno. Existem políticas estratégicas limitadas factíveis para resgatar formas simples de trabalho e renda como os Empreendimentos Econômicos Solidários (EES). Essa discussão que ocorre há pelo menos um século, e até a primeira década do século XXI não foram aprendidas lições estratégias de inclusão da agricultura familiar como alternativa para as famílias rurais que vivem da subsistência. Evidencia-se a importância do tema devido a desigualdade social que o Brasil enfrenta como um problema crônico, visto que milhares de famílias vivem de iniciativas como a ES para subsistência.
\end{abstract}

Palavras-chave: Objetivos do Desenvolvimento Sustentável (ODS); Agricultura sustentável; Empreendimentos Econômicos Solidários (EES); Redução da desigualdade social.

\begin{abstract}
Despite the difficulty of conceptualizing the Solidarity Economy (SE) due to interconnected themes and used interchangeably, it is mistaken in isolation from the context of economic development as an alternative for generating family income. With the social and economic reality of the regions of the extensive Brazilian territory, there is a blurring of the social function that HE plays in the field of Public Policies that make up family farming, which, among other developments in terms of government policies, is foreseen as one of the goals of the 17 Sustainable Development Goals for 2030, of the United Nations, characterized as a national and international development instrument. The method consists of descriptive and documental analysis, using a quantitative and bibliographic approach regarding the representation of data. A misalignment of the axes that foster public policies with sustainable development was found, and higher education was forgotten and to a certain extent suffocated by the capitalist system in which inclusive public policies are unable to absorb this phenomenon. There are limited feasible strategic policies to rescue simple forms of work and income such as Solidarity Economic Enterprises (SEE). This discussion has been going on for at least a century, and until the first decade of the 21 st century, strategic lessons were not learned for the
\end{abstract}


inclusion of family farming as an alternative for rural families who live on subsistence. The importance of the theme is highlighted due to the social inequality that Brazil faces as a chronic problem, as thousands of families live off initiatives such as higher education for subsistence.

Keywords: Sustainable Development Goals (SDGs); Sustainable Agriculture; Solidarity Economic Enterprises (SEE); Reduction of social inequality.

\section{Resumen}

A pesar de la dificultad de conceptualizar la Economía Solidaria (ES) por temas interconectados y utilizados indistintamente, se confunde aislada del contexto del desarrollo económico como alternativa de generación de ingresos familiares. Con la realidad social y económica de las regiones del extenso territorio brasileño, se desdibuja la función social que desempeña la ES en el campo de las Políticas Públicas que integran la agricultura familiar, que, entre otros desarrollos en términos de políticas gubernamentales, es prevista como una de las metas de los 17 Objetivos de Desarrollo Sostenible para 2030, de Naciones Unidas, caracterizada como un instrumento de desarrollo nacional e internacional. El método consiste en un análisis descriptivo y documental, utilizando un enfoque cuantitativo y bibliográfico en la representación de los datos. Se encontró una desalineación de los ejes que impulsan las políticas públicas con el desarrollo sostenible, y la educación superior fue olvidada y en cierta medida asfixiada por el sistema capitalista en el que las políticas públicas inclusivas son incapaces de absorber este fenómeno. Existen pocas políticas estratégicas factibles para rescatar formas simples de trabajo e ingresos como Empresas Económicas Solidarias (EES). Esta discusión lleva al menos un siglo, y hasta la primera década del siglo XXI no se aprendieron lecciones estratégicas para la inclusión de la agricultura familiar como alternativa para las familias rurales que viven de subsistencia. La importancia del tema se resalta debido a la desigualdad social que enfrenta Brasil como un problema crónico, ya que miles de familias viven de iniciativas como la educación superior para la subsistencia.

Palabras clave: Objetivos de Desarrollo Sostenible (ODS); Agricultura sostenible; Empresas Económicas Solidarias (EES); Reducción de la desigualdad social.

\section{Introdução}

No início de século XXI, a Economia Solidária (ES) sofreu manifestações sociais em diferentes perspectivas de discussão, desde o âmbito local a partir da agricultura familiar nas comunidades, cooperativas, Universidades, indústrias de produtos e na esfera da circulação de produtos no comércio popular, e em esfera nacional em termos de políticas públicas. O teórico Paul Singer, falecido em 2018, deixou um legado científico que possui vertentes com os objetivos dos programas de fortalecimento de mercado interno por intermédio de distribuição de renda, e apesar de Singer ter tido uma formação socialista, não concordava com a ideia de centralizar o planejamento econômico em grupos de integrantes, pois considerava isso antidemocrático e que viola direitos fundamentais previstos no ordenamento jurídico (Santos, 2018, p. 64).

Ocorrem tensões e incompatibilidades de interpretações que estão dessincronizadas com os objetivos da ES no âmbito da agricultura familiar, visto que esse desalinhamento dos objetivos em relação à prática tem ocasionado distanciamento do cumprimento dos objetivos do Desenvolvimento Sustentável (ODS) para 2030. A ES como perspectiva alternativa de renda e de sobrevivência representa um contínuo e longo processo de construção e definição em que o marco teórico prevê os objetivos em termos de políticas sociais. A ES se consiste em um conjunto de atividades práticas que possuem fatores que deságuam em cooperativismo, ética e empatia para preservar o bem-estar dos indivíduos e estimular o desenvolvimento econômico regional (García; Gómez; Castillo, 2017, p. 16). Não se pode esquecer que a ES é uma forma de intercâmbio de produtos para o consumo individual e coletivo da comunidade, tornando-se um caminho de trocas de experiências de cooperação, e desse modo identifica-se a hipótese de perda de identidade do conceito de ES.

A ES é um conceito reaberto no âmbito das políticas públicas para manter os fundamentos teóricos sobre as novas formações de mobilização e de organizações coletivas relacionadas a ES a partir das diferentes realidades (desde a perspectiva latino americana e no âmbito da União Europeia), em que os antecedentes históricos gravitam em torno de práticas sociais de economia informal. Na Europa, por exemplo, a ES surge com alicerce na "Economia Social", que teve origem francesa na década de 1970, no entanto, somente teve maior visibilidade no ano de 2000, com a criação da Plataforma Conferencia 
Europea Permanente de Cooperativas, Mutualidades, Asociaciones y Fundaciones (CEP-CMAF), mais tarde denominada de Social Economy Europe (Telles; Servós; Bittencourt, 2020, p. 2-3).

Para equilibrar a economia das famílias na década de 90, o emprego dos trabalhadores brasileiros entrou em crise em diversos setores econômicos, e a ES surge como alternativa de renda para dar uma resposta dos grupos sociais mais vulneráveis em relação ao sistema capitalista formado pelo monopólio industrial. Esse âmbito surge para ajustar as imperfeições que o mercado de produtos disponibiliza para parcela da população que está excluída do sistema de trabalho formalizado, pois essa iniciativa da ES surge como uma válvula de escape para famílias deslocadas das relações formais de trabalho (Singer, 2018, p. 159-160). As associações e as cooperativas desde sua essência possuem como objetivo a inclusão social e econômica desses trabalhadores organizados a partir de uma base democrática e para fortalecer o associativismo e organizações sindicais para lutarem a favor de seus direitos sociais.

O conceito de ES foi construído há décadas a partir de uma realidade latino-americana de suprimento dos postos de trabalho a partir de iniciativas informais, uma vez que os programas políticos e ao nível institucional demonstraram preocupação com essa desestruturação do mercado de trabalho em países que enfrentam problemas com o desenvolvimento econômico e social. O marco teórico na Economia Social na política nacional possui lastros na cooperação econômica e fomento de atividades de diversos setores econômicos com distintas finalidades (Silva, 2018a, p. 26). Embora haja um consenso sobre as origens da ES, ocorrem ramificações em outros temas como Economia Social, Economia da Solidariedade, Economia Rural que possuem relação intrínseca, no entanto, a ES ganhou espaço com a criação da Secretaria Nacional de Economia Solidaria (SENAES), compondo parte da estrutura do Ministério do Trabalho (MT). As ações governamentais que apoiam a ES foram divididas em quatro eixos: a organização público-comunitário, acessa a conhecimentos: educação e tecnologias, investimentos e finanças solidárias e organização da comercialização justa e solidária (Silva, 2018b, p. 164). A implementação como uma estratégia governamental na Política de Economia Solidária no Brasil se constituiu um desafio para agenda do Plenário Nacional, visto que as barreiras burocráticas e os interesses divergentes dos partidos políticos somaram-se aos debates legislativos para compor uma política unitária com objetivos convergentes na linha de estratégias políticas de ES.

A ES possui suas vertentes sociológicas que se alinham com temas da pobreza e a desigualdade, as questões socioeconômicas são debatidas em agendas constantemente por órgãos públicos e privados. A Agenda 2030 estabeleceu ações que visem fomentar e articular esforços para que a condição de vida da população se torne melhor, uma vez que o bem-estar social de um país é a prova de como as políticas públicas são criadas pelos governos (Nachtigall et al., 2020, p. 9). A busca por soluções como o desenvolvimento sustentável demonstra uma trajetória analítica da forma como o ser humano priorizou excessivamente o aspecto monetário em relação à qualidade de vida na sociedade em detrimento as mazelas problemáticas como desigualdade social que estão presentes. A ES se trata de um modo de produção familiar que alinha seus princípios para combater as vulnerabilidades socioeconômicas que existem em grande escala e sem uma perspectiva de resolução a curta e médio prazo. $\mathrm{O}$ objetivo se consistirá em analisar às políticas públicas, agricultura familiar e a perspectiva do desenvolvimento sustentável, levando-se em consideração, aspectos como cooperativismo, associativismo, EES, iniciativas legislativas e de fomento da agricultura familiar sustentável ao nível nacional.

A justificativa da investigação é divida em três âmbitos: a social que está ancorada como ocorrem as formas de integração das políticas públicas no contexto da agricultura familiar em um dos 17 Objetivos do Desenvolvimento Sustentável da agenda 2030 (ONU, 2021), precisamente no objetivo “2. Fome zero e agricultura sustentável”. A justificativa científica é sustentada por haver limitados estudos de viés multidisciplinar com integração de áreas jurídicas/sociais, políticas e econômicas. A justificativa social está balizada em iniciativas de integração de políticas públicas que possuem o objetivo de diminuição da desigualdade social. O estudo contribuiu na identificação de elementos como desalinhamento dos princípios e dos objetivos a partir da criação e do fomento das iniciativas de ES no âmbito da aplicação transversal nas regiões brasileiras. 
Isso também foi verificado no campo estratégico e político, em que ocorre incompatibilidade com a realidade social, resultando em uma espécie de ofuscamento ou até mesmo distanciamento do conceito de ES.

\section{Metodologia}

A construção da pesquisa está composta pela teoria de base/abordagem, procedimento e técnica. O método revestiu-se em análise descritiva e documental com abordagem quantitativa e bibliográfica dos dados. O procedimento foi realizado pela análise bibliográfica e documental com consulta em livros, e-books, sites e artigos de revistas direcionadas ao tema com alto fator de impacto. Utilizou-se como técnica a construção de resumos e observações que serviram como subsídio na formulação das hipóteses e nas conclusões apresentadas a partir das informações coletadas. A abordagem se consiste majoritariamente qualitativa, uma vez que foram utilizados dados de órgãos oficiais que foram adaptados para gráficos e tabelas, permitindo visualização do cenário em que se encontram as iniciativas relacionadas à ES no Brasil.

Houve a necessidade de balizamento de alguns objetivos específicos tais como i) previsões legislativas e evoluções das normas referentes a ES; ii) EES no âmbito brasileiro; e iii) análise do Objetivo 2. Fome Zero e agricultura sustentável prevista na Agenda do Desenvolvimento Sustentável para 2030. Para que fosse alcançado o objetivo na investigação, a estrutura e análise se consistiram em uma abordagem sobre aspectos conceituais, históricos e os objetivos da ES no âmbito nacional. Será realizada uma matriz transversal sobre os princípios da realidade social e econômica, bem como as relações de trabalho no âmbito da agricultura familiar. A proposta analisará os precedentes dos dispositivos jurídicos que se coadunam com as iniciativas da ES e suas as alterações legislativas na perspectiva da ODS 2030 e seus reflexos da pandemia (Covid-19).

\section{Resultados e Discussão}

\subsection{Princípios da Economia Solidária baseada no contexto da realidade social e econômica}

Os princípios da ES possuem reflexos nas medidas legislativas para atender as demandas com soluções concretas com alternativas exequíveis do ponto de vista da particularidade de cada região brasileira (Gaiger, 2020, p. 106). Os movimentos de participação da sociedade têm contribuído para criação de mecanismos jurídicos mais eficazes e transparentes para os cidadãos, tendo como exemplo, a base de dados do Sistema Nacional de Economia Solidária no Brasil (SIES), que é um portal de transparência vinculado ao Governo Federal. No âmbito brasileiro, a formação consolidada da ES como princípio foi desencadeada no período de 1997 até 2002, tendo como origem no encontro Latino-americano de cultura e socioeconômica solidária, realizado na capital de Porto Alegre - RS. Após as iniciativas governamentais e surgirem às primeiras discussões sobre a relevância do tema para o desenvolvimento de uma nação, surgem outras atividades sociais como o Primeiro Fórum Brasileiro de Economia Solidária (FBES), no ano de 2001 (Monteiro; Gonçalves, 2020, p. 2).

O contexto da realidade social implica nos vetores do poder público e o próprio Estado ao colaborarem com os agricultores que desenvolvem funções empreendedoras como a produção e comercialização própria. Se torna prejudicada a autogestão dos agricultores nas atividades que geram um complemento na renda mensal individual ou familiar dos agricultores, uma vez que é a única fonte de renda em situações de necessidade. A ES também possui relação com o princípio Constitucional da solidariedade, sendo entendida como uma forma de geração de renda e trabalho para auferir uma economia que serve como complemento de renda das famílias que estão sob o abrigo da economia familiar. Os objetivos da lei da ES são de promover o incentivo ao desenvolvimento de novas atividades econômicas, estimular as relações sociais de produção existentes e valorizar os indivíduos por meio da cooperação e da solidariedade. Por outro lado, devido à desigualdade social em praticamente todas as regiões brasileiras, assim como o efeito da pandemia (Covid-19), aumentaram as formas de atividades econômicas como empreendimentos individuais de ES. 
De acordo com o Observatório Nacional da Economia Solidária e do Cooperativismo (Onesc), que é um instrumento que é utilizado para produzir informações e estudos, essa iniciativa contempla a elaboração de soluções para os problemas sociais e serve como ferramenta para tornar pública informação aos gestores públicos na medida que fortalecem o tema da ES. Os últimos dados do Observatório são 2013, e registram que o número de EES informais chegou a 5.291, enquanto que os formais 2,985 (ONESC, 2013a, s./p.). Dentre os EES formais, destaca-se a região nordeste que contempla 25\%, porquanto, os EES informais encontram-se mais representativo na região sudeste com 24\% (ONESC, 2013b, s./p.).

O surgimento da EES é um dos campos que avançaram da ES no sentido tradicional contemplam critérios que são utilizados para diferenciar e classificar os EES. O vínculo social dessa iniciativa se estende para diversos campos sociais como os princípios da equidade e cooperação, assim como na questão da justiça social, pois é uma forma de engajar soluções para problemas como a desigualdade social, econômica e outras vertentes como as políticas públicas inclusivas. A Onesc classificou em valores absolutos os EES pelas Unidades da Federação nos anos de 2009 a 2013, sendo contabilizadas as seguintes divisões: comercialização ou organização da comercialização; consumo, uso coletivo de bens e serviços pelos sócios; poupança, crédito ou finanças solidárias; prestação do serviço ou trabalho a terceiros; produção ou produção e comercialização; troca de produtos ou serviços. O número total representa 19,708 empreendimentos que foram mapeados nesse período, uma vez que não há dados mais recentes sobre o número atualizado desses registros no SIES.

De acordo com o Censo Agro 2017, os estabelecimentos agropecuários representam 351 milhões de hectares no Brasil, refletindo um aumento de 5\% de área em relação ao censo anterior. Da área total de estabelecimentos no país, 80,9 milhões de hectares corresponde área ocupada pela agricultura familiar, contemplando $23 \%$ da área total. Os estados que lideram o tamanho de área ocupada pela agricultura familiar são Pernambuco, Ceará e Acre (IBGE, 2017a, [s./p.]). No entanto, cerca de 80\% dos estabelecimentos têm área menor que 50 hectares (IBGE, 2017b, [s./p.]), conforme (Figura 1).

Figura 1. Resultados definitivos do Censo Agro 2017.

\section{Tamanho do estabelecimento}

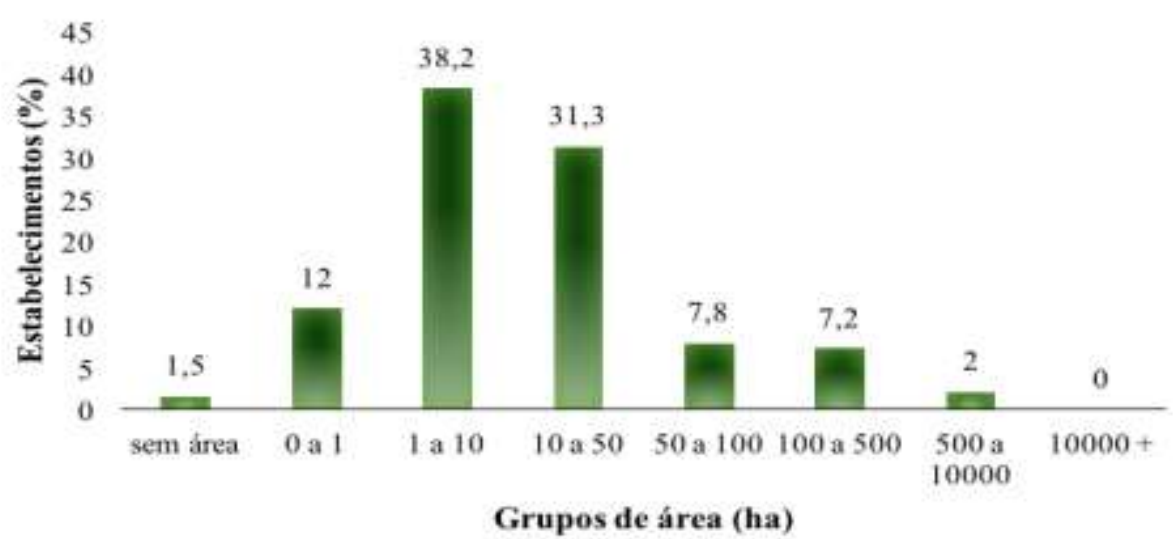

Fonte: IBGE, 2017b, [s./p.].

Apesar dos últimos dados disponíveis sobre os EES serem de 2013, o RS lidera no ranking federativo de empreendimentos a partir de uma ampla participação e integração de políticas públicas ao nível municipal e estadual. No grupo dos EES, grande parte dessa distribuição compreende trabalhadores no modo informal, tendo sua maior demanda no início da década de 90, do século passado, em que é contemplada a participação de associações, cooperativas, comunidades locais e outras espécies de organizações não formais de trabalhadores. As associações são as iniciativas com maior número de trabalhadores locais, sendo a forma de trabalho mais utilizada, seguida das cooperativas rurais em comparação com as 
cooperativas empresariais, pois aquelas possuem vantagens como a desburocratização jurídica, menor grau de formação profissional, participação na tomada de decisões da cooperativa (ONESC, 2013c, [s./p.]).

O princípio da ES é esquecido na discussão acadêmica referente à gestão de produção, visto que as condições socioeconômicas, desemprego e o trabalho informal deve ser analisado antes de iniciar o processo de gestão de produção. Um estudo revelou que a análise científica é fruto de artigos de outras modalidades de publicações relacionadas com temas da engenharia da sustentabilidade, e que existem limitados estudos da ES relacionados com áreas de engenharia de produção, logística e engenharia de Qualidade e produtividade (Curi Filho; Curi, 2020, p. 43639). A ES possui um escopo voltado para pesquisas empíricas específicas para determinadas áreas como política social, áreas agrárias, econômicas, sociologia, engenharia ambiental, entre outras. Todavia, há poucas iniciativas transversais em áreas de gestão de produtos, transporte e logística, venda e comércio de produtos, formação técnica, marketing da comercialização e sistemas organizacionais.

\subsection{Relações de trabalho na agricultura familiar sustentável}

Como política social e os movimentos sindicais no âmbito do cooperativismo e das baixas oportunidades de trabalho assalariado, esses fenômenos de reestruturação do capital das empresas foram sentidos rapidamente, uma vez que fecharam fábricas, aumento do desemprego e cresceram as formas de precarização do trabalho. Em resposta a esses fenômenos, houve a chamada Revolução Informacional que teve o objetivo eliminar as barreiras fronteiriças com a criação de empresas por redes conectadas, terceirização das atividades, flexibilização das jornadas de trabalho, bem como estreitamento dos direitos sociais a partir da segunda metade do século XX (Souza, 2018, p. 47-48). Essas modificações provocaram um novo cenário nas relações de trabalho, assim como surgiram correntes que enfraqueceram os sindicatos de trabalhadores na medida em que os direitos sociais foram encurralados pela flexibilização e intensificação das relações trabalhistas.

A concepção de relação de trabalho conforme estabelece a OIT, está alinhavada no sentido de princípios em que todos os trabalhadores devem buscar os direitos que contemplam o correto funcionamento no contexto social e com garantia da dignidade e de uma perspectiva de justiça social do trabalhador diante do mercado de trabalho (Barzotto; Oliveira, 2018, p. 143). A proteção ao trabalho se estende quando a OIT prescreve em seu preâmbulo que os níveis de proteção ao trabalho devem contemplar direitos conquistados rumo à progressão social. O art. 19, inciso VIII, do mesmo dispositivo, faz menção de que as normas nacionais serão aplicadas sempre no sentido mais favorável. Outro exemplo é a Convenção de 189, que foi ratificada pelo Brasil no ano de 2018, referente à proteção os (as) trabalhadores (as) domésticos (as).

Existe um estreito vínculo da agricultura familiar com a formação de cooperativas rurais para atender as demandas dos produtores com maior flexibilidade de deslocamento até os centros urbanos. Os agricultores familiares associados aos sindicatos e órgãos municipais, possuem linhas de crédito mais atrativas para realizarem investimentos para a produção e comercialização de produtos. Conforme o texto constitucional brasileiro, as cooperativas devem ser fomentadas pelos órgãos públicos competentes em relação às pequenas iniciativas de agricultura familiar, uma vez que se as cooperativas são a realidade mais próxima que uma família pode estar vinculada. As cooperativas são barradas de participar das licitações públicas devido ao fato que as cooperativas não estão sujeitas as normas trabalhistas, bem como devido aos Termos de Ajustamento de Conduta (TAC), firmado pelo Ministério Público do Trabalho (MPT) e as Cooperativas, uma vez que o objetivo é evitar o não cumprimento das leis do trabalho ou combater cooperativas irregulares, ou fantasmas. Por outro lado, esse aspecto acaba prejudicando àquelas que possuem seu registro e as atividades corretamente, pois exclui manter trabalhadores por meio de cooperativas de todas as formas de contratação de serviços como limpeza, conservação, recepção, cozinha e auxiliares, manutenção de prédios, telefonia, veículos, instalação elétrica entre outros setores econômicos.

A agricultura familiar possui vertentes em melhorar a capacidade integrativa da sociedade, tendo como foco economia de qualidade para os cidadãos a partir de iniciativas locais como associações, cooperativas, integração de comunidades, etc. Os 
Research, Society and Development, v. 10, n. 12, e60101220023, 2021

(CC BY 4.0) | ISSN 2525-3409 | DOI: http://dx.doi.org/10.33448/rsd-v10i12.20023

primórdios das relações de trabalho familiares se consistiam na gestão da propriedade da melhor forma possível, havendo a produção de alimentos para consumo próprio e suas tradições que seguem de geração em geração. Apesar de haver ampliado o conceito de família, a produção sustentável é desafiadora na medida em que a procura por produtos rurais livres de produtos químicos se tornou comum, havendo um mercado promissor para produtos orgânicos desenvolvidos pelos trabalhadores de ES.

A agricultura familiar tem demonstrado que é à base de produção de alimentos para subsistência de famílias distribuídas nas diversas regiões que compreendem a enorme extensão territorial do Brasil. Essas formas de empreendimentos das associações agrícolas familiares se referem ao viés empreendedor individual ou no âmbito familiar pode desenvolver, alinhavada a perspectiva cooperativa que é aquela que surge das famílias tradicionais em compreender a necessidade de redes de ajuda para garantir a subsistência. O trabalhador rural é considerado parte frágil nas relações de trabalho, vindo a importar em direito de dispor de seu trabalho na medida que vende sua força de trabalho em moeda. Em meados do século XIX, Marx (2013, págs. 312-320), já alertada que as diferenças nas relações de trabalho ampliavam-se quando surgiu a mais-valia, em que o empregador planeja um excedente que não the era pago, gerando um acúmulo de capital nas mãos dos empregadores.

A agricultura familiar sustentável e o cooperativismo são elementos inseparáveis para que as políticas de desenvolvimento econômico familiar possam resultar exitosas. As cooperativas são instrumentos fundamentais de apoio aos agricultores familiares, pois reduzem custos quando adquirem insumos agrícolas e na contratação de serviços como transportes da produção, aquisição de maquinários agrícolas entre outros benefícios (Freitag; Klesener; Plein, 2019, p. 95). O viés da sustentabilidade assemelha-se na linha da interação social e capacidade de desenvolvimento da produtividade agrícola, pois a competitividade por produtos alimentícios sustentáveis e saudáveis para consumo se constitui em um dos temas mais debatidos pelos órgãos de saúde nacionais e internacionais. A agricultura sustentável, portanto, o modo de produção agrícola desenvolvido de uma geração familiar para outra a partir da subsistência que é transferida por intermédio de conhecimento e principalmente prática de produção de alimentos. Para que se torne exequível que os produtores familiares possam desenvolver técnicas adequadas no manejo e produção de alimentos, caberá ao Estado proporcionar, através de políticas inclusivas, viabilizar que a agricultura familiar se torne uma ferramenta atrativa e acessível na produção de alimentos sustentáveis e econômicos, contribuindo para o avanço positivo em outros objetivos da Agenda 2030 (Benites; Trentini, 2019, p. 4).

Os estímulos legislativos que o Governo Federal proporcionou em contribuição com a agricultura familiar contempla o Programa de Aquisição de Alimentos (PAA), que é uma iniciativa em que os alimentos são distribuídos para população vulnerável e com a condição alimentar insegura, assim como para aquelas famílias em condições sociais e econômicas graves. O Programa Nacional de Alimentação Escolar (PNAE), gestionado pelo Fundo Nacional de Desenvolvimento e Educação (FNDE), com previsão legal na Lei n. ${ }^{\circ} 11.947 / 09$, possui objetivo de desenvolver ações na área da educação alimentar e acompanhamento nutricional nas escolas, tendo como fornecedores de produtos alimentícios os agricultores locais e regionais para manter a cadeia produtiva de alimentos e os consumidores voltados para um ciclo estratégico de desenvolvimento local.

O modelo de agricultura moderna que utiliza mão-de-obra de trabalhadores fixos ou por temporada, desde pequenas, médias ou grandes propriedades, com salários fixos ou relacionados à produção, utiliza o cultivo de suas próprias terras ou por arrendamento para sobrevivência do núcleo familiar (Borges et al., 2020, p. 4). Por outro lado, a agricultura extensiva é responsável pela produção de produtos alimentícios do país, no entanto, enfrenta dificuldades na escoação dos produtos para exportação para outros países, comercialização ao nível local, uma vez que o mercado exigente e burocrático cria barreira que impedem que os produtos possam ser escoados para o mercado consumidor.

Conforme pesquisa realizada por Borges et al. (2020, p. 11), com trabalhadores que vivem da subsistência da agricultura familiar, aproximadamente $26,30 \%$ dos indicadores de sustentabilidade são desfavoráveis devido a dificuldades como acesso à água para fins de agricultura, esgoto, análise técnica para correção do solo, orientação e participação ativa de cooperativas para exportação dos produtos e baixo incentivo de ajuda de programas do Governo Federal para pequenos 
agricultores. É notória a fragilidade que o âmbito ambiental possui para o cumprimento de um dos 17 Objetivos do Desenvolvimento Sustentável para 2030, e desse modo ocorre uma dessincronia abismal das políticas públicas agrárias para alcançar resultados benéficos para os trabalhadores agrícolas das regiões brasileiras.

\subsection{Alterações do Projeto de Lei da Câmara n. ${ }^{\circ}$ 137, de 2017, sobre a Política Nacional de Economia Solidária}

Antes de adentrar sobre as alterações do Projeto de Lei 137/2017, deve ser entendido que a ES possui como definição horizontal conforme prevê a organização das Nações Unidas para Alimentação e Agricultura, como a inclusão de atividades agrícolas que possuem o aspecto da organização familiar juntamente com a produção agrícola, pastoreio, florestal, administrativa entre outras atividades que dependem da participação da mão de obra familiar (FAO; IFAD, 2019, p. 10). Em um país como o Brasil, que possui uma diversidade regional e estadual imensa, essa definição foi fragmentada para realidade social, uma vez que no mesmo território é possível identificar biomas distintos, portanto, desenvolvem-se atividades completamente distintas tendo em vista os aspectos mais adequados de cada região.

Conforme o Parecer N N $^{\circ} 27$, de 2019, do Plenário do Senado Federal, referente ao Projeto de Lei supracitado, em que consta com o expediente remitida à Câmara dos Deputados, em 18 de dezembro de 2019, contempla integração de estratégias de desenvolvimento sustentável, EES, prevê a definição de Empreendimentos Beneficiários, trabalho cooperativo, medidas para educação, conhecimento técnico e a criação de um Fundo de Economia Solidária (BRASIL, 2019, págs. 1-7). A literatura é pacifica quanto ao objeto que a ES abrange em termos de conjunto de atividades organizacionais das famílias com menor possibilidade de participar do mercado competitivo em média e grande escala. Essas possibilidades contribuem para que ocorra a democratização da própria economia popular, uma vez que os indivíduos buscam integrar princípios como da satisfação das necessidades individuais e coletivas. Os objetivos da ES estão alinhavados com a participação institucional de órgãos públicos e privados na busca de enfrentar questões como o incentivo das famílias para proporcionar o interesse coletivo.

$\mathrm{Na}$ América Latina a Economia Social vem sofrendo embates com o aperfeiçoamento do sistema capitalista do século $\mathrm{XX}$ em que essas formas de economia se tornam atrofiado. Algumas das razões se consistem nas perdas dos movimentos sociais operários e na dominação da esfera mercadológica sobre o Estado. Nesse momento, tanto o mercado gerando lucros e se autogestionando, assim como as funções do Estado passaram a gerar riquezas para assistência social, na qual o aspecto da Economia Social vem perdendo espaços. Quando ocorreram essas mudanças que o mercado dominante capitalista trouxe, houve uma desestruturação no campo social, político e econômico, na qual as formas de economia tradicional em pequena escala tiveram que se reinventar para reincorporar no contexto mais de mercado competitivo.

Sobre as alterações legislativas previstas no Projeto de Lei 137/2017, o referido dispositivo prevê a qualificação de empreendimentos da economia solidária no contexto das políticas públicas, bem como cria o Sistema Nacional de Economia Solidária (Sinaes), que possui o objetivo de fomentar as iniciativas de trabalhos em cooperativas e associações. A ES abarca atividade como organização da produção e a sua comercialização de serviços e de bens, assim como a distribuição do consumo em que são observados princípios como a autogestão, comércio justo, cooperação, solidariedade, participação democrática, distribuição equitativa, desenvolvimento local e nacional, preservação do meio ambiente e a valorização do trabalho.

A partir dos precedentes da ES e das iniciativas legislativas como o referido PL n. ${ }^{\circ}$ 137, de 2017, essas propostas em termos de implantação no modelo de desenvolvimento de programas oficiais do Governo Federal, ocorrem discrepâncias em termos práticos que precedem a inclusão de política pública, com efeito, eficaz sobre os resultados. O primeiro aspecto se consiste em dificuldades para trabalhar com questões voltadas para desigualdade social, luta pelo poder político e econômico, formas eficientes de autogestão de pequenos mecanismos como é o caso da agricultura familiar, que está inserida no contexto da ES, formas objetivas de redistribuição de renda e oportunidades para pequenos negócios familiares. Desse modo, ocorre a 
Research, Society and Development, v. 10, n. 12, e60101220023, 2021

(CC BY 4.0) | ISSN 2525-3409 | DOI: http://dx.doi.org/10.33448/rsd-v10i12.20023

dessincronização legislativa na criação de instrumentos jurídicos que não atendem a realidade local de associações, cooperativas ou grupos comunitários para se tornarem empreendedores familiares.

Com escopo em políticas nacionais de economia solidária, se torna desafiador para os países programarem novas formas de organização social e de trabalho e renda para classe trabalhadora vulnerável. Os precedentes sobre as novas organizações ou formas de trabalho persistem tradições racionalistas com raízes no neoliberalismo, uma vez que no momento que os modelos tradicionais transnacionais que dominam o mercado global sofrem impactos das crises econômicas, políticas e sanitárias (como é o caso da pandemia), indubitavelmente, a necessidade de os trabalhadores buscarem novas alternativas capazes de suprir a demanda por um emprego para sustento familiar. Os modelos de desenvolvimento econômico ao passo que avançavam com ferramentas tecnológicas e desenvolvimento científico avançado para época, tropeçavam em quesitos como oportunidades para grande massa de trabalhadores que vivem no âmbito informal em que não há registro junto à seguridade social, plano de saúde individual e familiar, integração social, contribuição sindical e previdenciária entre outros aspectos.

\subsection{Perspectiva da Agenda 2030 e estudos de casos a partir dos reflexos da pandemia (Covid-19)}

A ES se tornou uma alternativa de negócios que tem alcançado múltiplas possibilidades de geração de renda no contexto da pandemia. As formas de incorporações das novas metodologias de trabalho são oriundas das reconfigurações das relações na qual uma delas é a ES, uma vez que novos princípios e negócios são gerenciados e renascem iniciativas devido aos efeitos que a pandemia proporcionou. As formas de desenvolver a contribuem para o cumprimento do objetivo " 2 . Acabar com a fome, alcançar a segurança alimentar, a melhoria da nutrição e promover a agricultura sustentável” (Brasil, 2016, [s./p.]), que contempla a Agenda 2030 da ONU. Esse eixo surge como para entidades com o objetivo de estimular à sustentabilidade ambiental do planeta. A geração de trabalho e renda possui um elo fundamental na questão da política estratégica dos governos, uma vez que novas formas de análise multidimensional proporcionam uma análise transversal na criação de estratégias eficientes como cooperação e solidariedade no contexto das entidades públicas e privadas de todo país.

A pandemia proporcionou um cenário de restrições de mobilidade que elevou a carga psicológica devido ao aspecto de milhões de pessoas sendo contagiadas e outras tantas que não sobreviveram ao vírus mais letal da virada da primeira década do século XXI. As perdas humanas são incalculáveis devido à situação extraordinária que afetou e continua afetando as relações sociais, impondo restrições nos abastecimentos de alimentos, perdas de empregos em massa, diminuição de renda familiar, educação comprometida para indivíduos que não possuem acesso às plataformas digitais, etc. Para Urcola e Nogueira (2020, p. 46), a pandemia impactou transversalmente a produção de alimentos oriundos da agricultura familiar e leva a repensar sobre o papel fundamental dos sujeitos que produzem alimentos sustentáveis como forma de manter uma alimentação para reforçar o sistema imunológico do ser humano.

Os 17 ODS que foram propostos para serem cumpridos para 2030, são desafios que estão distantes da realidade social e econômica dos países, uma vez que há diferenças gritantes quanto à forma como países europeus lidam com essa questão em relação aos países sul-americanos. $\mathrm{O}$ aspecto abissal no período de pandemia é que o espaço das iniciativas particulares como pequenos empreendimentos rurais como vendas de produtos alimentícios, artesanatos, produções de produtos foi aumentando na medida em que as restrições foram determinadas pelas autoridades sanitárias, chegando ao momento que as autoridades competentes para criar políticas públicas que reconheçam a importância da agricultura familiar (FLOR, 2020, p. 105).

Em uma visão de política estratégica dos países europeus que possuem um alinhamento das cooperativas rurais com os Sindicatos de Trabalhadores Rurais (STR), o objetivo foi evitar a precarização dos trabalhadores devido aos grandes empreendimentos sufocarem as pequenas iniciativas. Por outro lado, esses temas já se tornaram disputas no Ministério do Trabalho (MT), com diversas ações trabalhistas e civis que envolvem temas relacionados a propostas de soluções para cooperativas e grandes empresas já consolidada no ramo do mercado de produtos. 
Um dos entraves para ES é justamente o crédito ou acesso ao capital que as famílias da agricultura familiar enfrentam para realizar investimentos em pequenos empreendimentos. O papel que as empresas como o Banco Central realizam como fomento para as pequenas iniciativas da agricultura familiar são baixíssimas, uma vez que as famílias mais necessitadas mesmo que se encontre em programas de ajuda governamental, possuem poucas possibilidades de realizar empréstimos junto às instituições financeiras. $\mathrm{O}$ sistema de microcrédito brasileiro surge de um contexto capitalista que se modificou da ideia básica surgida pelo projeto Grameen, que inicialmente foi desenvolvida pelo Serviço de Apoio à Micro e Pequenas Empresas (SEBRAE), vinculado ao Banco Nacional de Desenvolvimento Econômico (BNDS). Essas iniciativas possuem como objetivo o empreendimento individual em que as famílias com pequenas perspectivas de trabalho formal para se tornarem empreendedores de diversas áreas como apicultura, hortas urbanas e venda de alimentos em feiras como verduras, verduras, cooperativas de leite, produtos coloniais como queijo, embutidos, etc.

No amplo objetivo da Agenda 2030, no item 10, "redução das desigualdades sociais", em curto prazo, exporta uma realidade distinta sobre a diversidade da realidade brasileira em termos sociais, econômicos e ambientais (Mahnic; Santos; Bellen, 2020, p. 55). O autor Enrique Leff já comentava no início do século XX, que desde o início o tema da sustentabilidade foi analisado sobre modo de repensar as formas produtivas dos alimentos e da própria economia de mercado, visto que deve ser desvinculado da ideia de globalização que é outro tema que não é bem compreendido.

Como exemplo da importância de economias de pequenas comunidades através da venda de produtos cultivados no local, está situada na Serra Norte do Equador uma província chamada Imbabura. Trata-se de uma zona rural em que os habitantes sobrevivem de atividades rurais (agricultura e comércio de produtos agrícolas). A agricultura é a principal fonte de renda em que os trabalhadores e proprietários das terras de plantio são grandes fazendeiros, empresas multinacionais e parte do Estado na qual os trabalhadores pagam para manter suas colheitas. Se não bastasse às dificuldades em cumprir todos os custos financeiros e realizar trabalhos ao sol diariamente, a situação da mulher também é difícil, uma vez que as mulheres rurais (na maior parte indígena), que historicamente sofrem exclusões sobre o acesso à educação, muitas das moradoras em locais são analfabetas em seu idioma nativo. A partir de 2009, através do Movimiento de Economía Social y Solidaria del Ecuador (MESSE), iniciaram modos de comercialização de produtos em que $80 \%$ das mulheres rurais de diversos povos antigos (Karanki, Pasto, Natabuela, Kayampy, Otavalo, etc.), estão obtendo formas de subsistência junto as cidades próximas (Murillo, 2017, p. 26-27).

A relevância da agricultura familiar se tornou visível devido aos reflexos que a pandemia proporcionou e continua impactando no âmbito da recuperação econômica dos países afetados. O Paraguai é o país com maior número de agricultores com unidades produtivas familiares da região em relação à população. Com o avanço da pandemia, houve uma revalorização das atividades rurais por se tratar de uma área com menor risco de contágio por haver menor densidade populacional. O governo paraguaio apresentou um plano de recuperação econômico chamado Napúa Paraguay, contemplando reformas em todo sistema estatal. Conforme imas (R). (2020, p. 25-26), para que haja efetividade do cumprimento dos 17 ODS na perspectiva de pandemia e superação da pobreza, o estudo dos seguintes pontos se mostra imprescindíveis: apoio integral e sustentável a agricultura; inserção dos trabalhadores rurais e agropecuaristas com oportunidades de emprego e renda; cobertura dos serviços de saúde e educação; e investimento em infraestrutura de bens e serviços coletivos.

A pandemia provocou caos na saúde pública em países como a Argentina, em que a quarentena provocou uma mudança de estratégia dos agricultores familiares. Como a mobilidade dos cidadãos foi restringida, e continua sendo em algumas áreas de grande risco, fortaleceram-se iniciativas como "circuitos comerciales cortos", sendo representados em grande maioria por feiras, entregas a domicílio, trabalhadores intermediários, freelancers, etc. Apesar de a venda de produtos em feiras não ser de forma direta, pois há uma logística de transporte na maioria dos casos, se trata de produtos da agricultura familiar que possuem interesses pelos consumidores por se tratar de produtos frescos e livre de utilização de produtos 
químicos. A venda direta ou aproximação dos agricultores dos consumidores promovem melhores condições de venda e de interação entre cidadãos. Por outro lado, a pandemia estimulou o valor dos alimentos saudáveis diretos do campo para revitalizar aspectos como sistema imunológico (Viteri, Vitale; Quinteros, 2020, p. 4-5).

No lastro da Economia Social Solidária em tempos de covid-19, no Uruguai, adotaram-se estratégias para frear os efeitos negativos que refletem no desenvolvimento agrícola do país. Para Trigo et al. (2020, p. 166), o primeiro aspecto que a crise provocou foi adotar uma medida de caráter coletivo em que aspectos como redes de inter-cooperação entre entidades e cidadãos. Esse aspecto está alinhado com a ES a partir da busca mútua de soluções para os problemas provocados com as restrições sanitárias, em que a crise revisitou conceitos como consumo responsável, uma vez que os alimentos se tornaram valorizados devido a fatores como bloqueio de importações de produtos e outros derivados de logísticas de transporte.

\section{Considerações Finais}

O primeiro aspecto identificado nesse ensaio teórico é que a definição de ES como política pública inclusiva está de acordo com a hipótese que houve uma perda da identidade e até um desalinhamento legislativo sobre os princípios pelos seguintes argumentos. Primeiro, observa-se que os precedentes da inserção da ES em âmbito latino-americano e, no caso do Brasil, foi fomentado para atender as demandas como desemprego, desigualdade social, econômica, problemas ambientais, desenvolvimento empresarial interno precarizado, fragmentado e incompatível, fome, pobreza entre outros efeitos que sistema capitalista alinhavado no discurso da globalização propôs para países que não se adequaram a esse modelo desenvolvimentista. O segundo diagnóstico é que as políticas públicas não conseguem enfrentar esses problemas com integração comunitária para combater os efeitos maléficos de um país com desigualdade econômica e social que afeta milhões de indivíduos.

Em relação aos princípios da ES voltados para realidade social brasileira, considerou-se que, é um tema que remete a outros âmbitos cujos objetivos são mútuos e transdisciplinares. No aspecto do número de EES por condição de formalização, segundo ano do início do empreendimento no Brasil, o nível, informalidade teve um acréscimo no período de 1983-2013, de 301 para 5,291 empreendimentos, enquanto que, o número de EES formais, aqueles que possuem registro junto ao órgão público competente, teve um acréscimo de 1983-2003, de 332 para 5,047. Por outro lado, os empreendimentos formais absolutos houve decréscimo de 2003 para 2013, totalizando de 5,047 para 2,985.

No âmbito da agricultura familiar sustentável, se conclui que esse modelo possui como objetivo que as famílias rurais possam obter seus alimentos saudáveis e sustentáveis individualmente, bem como alinhavar seus métodos com políticas de preservação do meio ambiente, pois é evidente e indiscutível que os impactos ambientais e para saúde humana devem ser considerados no contexto de uma produção sustentável. Isso é demonstrado na medida que a ES é um dos pilares que sustentam os 17 ODs para 2030, no entanto, se apresenta com tímidas iniciativas legislativas e de fomento de políticas voltadas para a esfera local e regional do imenso território brasileiro. Confirma-se a segunda hipótese de haver uma dessincronização ou — um desalinhamento na criação de iniciativas como os EES e criação de associações e cooperativas rurais locais, tornando-se um obstáculo para famílias e comunidades locais se tornarem pequenos e médios empreendedores.

De tudo que foi exposto sobre a proposta sobre a ES, com adendo da pandemia, este estudo não possui pretensão de esgotar esse tema complexo. Por outro lado, enfatiza a necessidade de rever e reflexionar conceitos como a geração de trabalho e renda em diversas dimensões como social, política, econômica, ambiental, trabalhista, tributária e previdenciária. Há necessidade de analisar a contribuição do trabalho da agricultura familiar sustentável não unicamente voltada para geração de renda, mas como uma forma de participação e reconhecimento para concretização do bem-estar. 
Research, Society and Development, v. 10, n. 12, e60101220023, 2021

(CC BY 4.0) | ISSN 2525-3409 | DOI: http://dx.doi.org/10.33448/rsd-v10i12.20023

\section{Agradecimentos}

A Universidad de Burgos (ESP) e a Universidade Federal de Pelotas (BRA).

\section{Referências}

Barzotto, L. C. \& Oliveira, O. M. B. A. de. (2018). OIT: solidariedade e fraternidade na proteção aos direitos humanos dos trabalhadores. Revista da Faculdade de Direito da UFRGS, 1(39), 141-156. https://doi.org/10.22456/0104-6594.84689

Benites, R. G. \& Trentini, F. (2019). Agricultura familiar sustentável: entre o desenvolvimento sustentável e a segurança alimentar. Revista de direito agrário e agroambiental, 5(2), 01-19. https://www.indexlaw.org/index.php/rdaa/article/view/5813/pdf

Borges, I. M. S., Almeida, R. L. J., Lima, C. A. O., Fernandez, A. C. G., Gomes, R. M., Oliveira, Silvio S. P. de, Oliveira, L. P. de, Silva, M. E. G. da, Araújo, W. da S. \& Simões, A. R. (2020). Agricultura familiar: análise de sustentabilidade através de indicadores sociais econômicos e ambientais. Research, Society and Development, 9(4), 1-14. https://doi.org/10.33448/rsd-v9i4.2832

Brasil. (2009). Lei n. ${ }^{\circ} 11.947$, de 16 de junho de 2009. Dispõe sobre o atendimento da alimentação escolar e do Programa Dinheiro Direto na Escola aos alunos da educação básica, altera as Leis nos 10.880, de 9 de junho de 2004, 11.273, de 6 de fevereiro de 2006, 11.507, de 20 de julho de 2007, revoga dispositivos da Medida Provisória no 2.178-36, de 24 de agosto de 2001, e a Lei no 8.913, de 12 de julho de 1994, e dá outras providências. http://www. planalto.gov.br/ccivil_03/_ato2007-2010/2009/lei/111947.htm

Brasil. (2017). Projeto de Lei de Câmara $n^{\circ} 137$, de 2017. Dispõe sobre a Política Nacional de Economia Solidária e os empreendimentos econômicos solidários, cria o Sistema Nacional de Economia Solidária e dá outras providências. https://legis.senado.leg.br/sdleg-getter/documento?dm=7268323\& ts $=1630441119210 \&$ disposition=inline

Brasil. (2019). Parecer $N^{\circ}$ 287, de 2019 - PLEN/SF. Redação para o turno suplementar do Projeto de Lei da Câmara ${ }^{\circ} 137$, de 2017 (n ${ }^{\circ} 4.685$, de 2012 , na casa de origem), nos termos da Emenda $n^{\circ} 1-$ CCJ/CDR/CAE (Substituto). https://legis.senado.leg.br/sdleggetter/documento?dm=8055797\&ts =16304411 20179\&disposition=inline

Brasil. (2016). Acompanhando a Agenda 2030. https://www.br.undp.org/content/brazil/pt/home/library/ods/acompanhando-a-agenda-2030.html

Curi Filho, W. R. \& Curi, L. dos S. (2020). Economia Solidária: um estudo bibliométrico de 10 anos no ENEGEP. Brazilian Journal of Development, 6(7), 43629-43641. https://doi.org/10.34117/bjdv6n7-106

Fao, Ifad. (2019). “United Nations Decade of Family Farming 2019-2028”. Global Action Plan, Rome. http://www.fao.org/3/ca4672en/ca4672en.pdf

Flor, F. H. (2020). Frente a la pandemia: potencialidades de la ruralidad y las agriculturas campesinas. Boletín Académico "Sociologia y Política HOY”, (4), 103-113. https://revistadigital.uce.edu.ec/index.php/hoy/article/view/2583/2905

Freitag, C., Klesener, H. M. \& Plein, C. (2019). Contribuições do cooperativismo solidário para agricultura familiar e o desenvolvimento rural sustentável. Revista Orbis Latina, 9(1), 95-109. https://revistas.unila.edu.br/orbis/article/view/1526/1417

Gaiger, L. I. (2020). Economia solidária, ativismo sociopolítico e democracia. Revista crítica de humanidades, Cadernos do CEAS, 45(249), 83-110. http://dx.doi.org/10.25247/2447-861X.2020.n249.p83-110

García, N. M., Gómez, F. M. \& Castillo, S. C. (2020). Reflexiones en tordo a la economía solidaria: una revisión de literatura. Iztapalapa. Revista de Ciencias Sociales y Humanidades, 38(83), 11-42. https://doi.org/10.28928/revistaiztapalapa/832017/atc1/martinezgomezf/colincastillos/manriquezgarcian

IBGE. (2017a). Censo Agropecuário 2006/2017. Agricultura Familiar. https://censoagro2017.ibge.gov.br/templates/censo_agro/resultadosagro/pdf/agricultu ra_familiar.pdf

IBGE. (2017b). Censo Agropecuário 2006/2017. Estabelecimentos. https://censoagro2017.ibge.gov.br/templates/censo_agro/resultadosagro/pdf/estabelecime ntos.pdf

IMAS R. V. J. (2020). Agricultura Familiar, ODS y recuperación económica post pandemia. https://www.decidamos.org.py/wp-content/uploads/2020/10/ Agricultura-Familiar-ODS.pdf

Mahnic, C. de L. P., Santos, D. F. \& Bellen, H. M V. (2020). Um retrato avaliativo dos objetivos de desenvolvimento sustentável nas capitais brasileiras. Grifos, 29(50), 52-74. https://doi.org/10.22295/grifos.v29i50.5214

Marx, K. (2013). O capital: crítica da economia política: Livro I: o processo de produção do capital. Tradução de Rubens Enderle. (Boitempo, Ed.).

Monteiro, L. M. \& Gonçalves, S. de L. (2020). Os empreendedores políticos da economia solidária no Brasil: as ideias de Singer, Gaiger e Arruda. Interseções, 22(1), 1-13. DOI: 10.12957/irei.2020.51162

Murillo, R. (2017). Mujer rural: nuevos roles en los procesos alternativos de comercialización directa. In Atienza, M. El Enfoque de género en la economía social y solidaria: aportes de la economía feminista. Madrid. España.

Nachtigall, Y. D. L., Viola, M. da S., Gonçalvez, G. E. \& Oliveira, S. V. de (2020). Estratégias em promoção aos objetivos de desenvolvimento sustentável: Experiências com a reprodução de tecnologias sociais no Brasil. Economia e desenvolvimento, 32(8), 01-10. https://doi.org/10.5902/1414650941490

ONESC. (2013a). Observatório Nacional da Economia Solidária e do Cooperativismo. Condição de formalização e erro. https://ecosol.dieese.org.br/imagens/ zoom1.png 
Research, Society and Development, v. 10, n. 12, e60101220023, 2021

(CC BY 4.0) | ISSN 2525-3409 | DOI: http://dx.doi.org/10.33448/rsd-v10i12.20023

ONESC. (2013b). Observatório Nacional da Economia Solidária e do Cooperativismo. EES e condição de formalização. https://ecosol.dieese.org.br/imagens/ zoom2.png

ONESC. (2013c). Observatório Nacional da Economia Solidária e do Cooperativismo. EES por Atividade Econômica Principal. https://ecosol.dieese.org.br/ ws $2 /$ tabela/economia-solidaria/empreendimentos-de-economia-solidaria-por-atividade-economica-principal

ONU . (2021). La Agenda para el Desarrollo Sostenible. https://www.un.org/sustainabledevelopment/es/development-agenda/

Santos, A. M. dos. (2018). Paul Singer: una vida por otra economia. Otra Economía, 11(20), 40-73. https://revistaotraeconomia.org/index.php/otraecono $\mathrm{mia} / \mathrm{article} / \mathrm{view} / 14756$

Silva, S. P. (2018a). O campo da pesquisa da Economia Solidária no Brasil: abordagens metodológicas e dimensões analíticas. (Ipea, Ed.).

Silva, S. P. (2018b). Crise de paradigma? A política nacional de Economia Solidária no PPA 2016-2019. Mercado de Trabalho. (Ipea, Ed.).

SINGER, P. (2018). Ensaios sobre economia solidária. (Almedina, Ed.).

Souza, A. R. (2018). Professor Paul Singer e a economia solidária. Revista P2P e INOVAÇÃO, 5(1), 43-52. https://doi.org/10.21721/p2p.2018v5n0.p43-52

Telles, L. B., Servós, C. M. \& Bittencourt, J. V. M. (2020). Las perspectivas Latinoamericana y Europea de la Economía Solidaria. REVESCO. Revista de Estudios Cooperativos, 134(e69171), 1-10. https://doi.org/10.5209/reve.69171

Trigo, G. S., Alén, F. S., Assandri, C., Álvarez, D. B., Carrero, D. C., Silva, C. M., Marichal, W. O., Cabrera, D. O., Pereiyra, J. R. C. \& Iglesias, G. V. (2020). Economía Social y Solidária y Covid-19 en Uruguay: estratégias de adecuación e incertidumbres en las organizaciones de la economía social y solidária en el marco de la emergencia sanitaria. Otra Economía, 13(24), 152-169. https://www.revistaotraeconomia.org/index.php/otraeconomia/article/ view/14915

Urcola, M. A. \& Nogueira, M. E. (2020). Producción, abastecimiento y consumo de alimentos en pandemia: El rol esencial de la agricultura familiar en la territorialidad urbano-rural en Argentina. Eutopía. Revista de Desarollo Económico Territorial, (18), 29-48. https://revistas.flacsoandes.edu.ec/eutopia/article /view/4629.

Viteri, M. L., Vitale, J. A. \& Quinteros, G. (2020). Innovar en tiempos de pandemia. Agricultura familiar en la Argentina. Balcarde. Argentina. 